\title{
COMO OCORRE O PROCESSO DE FORMAÇÃO DE ESTRATÉGIAS EM INSTITUIÇÕES DE ENSINO SUPERIOR? - UM ESTUDO EM SANTA CATARINA
}

\section{RESUMO}

O objetivo deste trabalho é conhecer o processo de formação de estratégia das IES localizadas no Estado de Santa Catarina, sob quatro enfoques teóricos: processo planejado, negociado, construção permanente e de mudanças, a partir da introdução e repercussão da LDB 9.394/96. Em termos metodológicos, esta pesquisa assumiu abordagem quantitativa, com uso do método survey. Quanto à natureza se classifica como descritiva, exploratória e explicativa. Constituiu instrumento de coleta questionário composto por 41 questões fechadas do tipo Likert de cinco pontos e dois quadros associativos para os respondentes numerarem por ordem de importância as condicionantes para a formação de estratégias. Os questionários foram distribuídos durante o período de março e abril de 2011, às 61 IES catarinenses, não obtendo retorno de 20 instituições. Os dados foram tabulados e receberam tratamento estatístico através do software Statistical Package for the Social Sciences - SPSS versão 20.0, fazendo-se uso da estatística multivariada para fins de análise. Os resultados remontam que o processo de formação de estratégia é fortemente influenciado pelo ambiente tarefa e pelas variáveis do ambiente geral e que as IES percebem sua estratégia como sustentada pelo processo planejado. Este estudo proporcionou melhor compreensão de como as estratégias em IES são formadas face às condições ambientais e as escolhas que os dirigentes fazem para cumprir seus propósitos, visto que o desempenho por elas apresentado tem forte relação com as políticas administrativas adotadas, mas principalmente pelas implicações que as decisões estratégicas adotadas têm contribuído para sua evolução.

Palavras-chave: Estratégia; Instituição de Ensino Superior; LDB 9.394/96.

\section{HOW DOES THE STRATEGY FORMATION PROCESS OCCUR IN HIGHER EDUCATION INSTITUTIONS? - A STUDY IN SANTA CATARINA, BRAZIL}

\begin{abstract}
The objective of this work is to know the process of strategy formation of HEI in the State from Santa Catarina, under four theoretical approaches: process planned, negotiated, permanent construction and change, from the introduction and impact of LGB 9.394 / 96. In terms of methodology, this research took a quantitative approach, using the survey method. This research is classified methodologically as descriptive, exploratory and explanatory. Constituted questionnaire collection instrument composed of 41 closed and objective questions Likert five points type and two associative tables for respondents to relate in order of importance the conditions for the formation of strategies. The questionnaires were distributed during the period of March and April 2011, at 61 HEIs from Santa Catarina, not getting return of 20 institutions. The data were tabulated and received statistical treatment through the software Statistical Package for the Social Sciences - SPSS version 20.0, making use of multivariate statistics for analysis purposes. The results go back to the process of strategy formation is strongly influenced by the task and the variables of the overall environment and atmosphere that HEIs realize its strategy as supported by the planned training strategies process. This study provided a better understanding of how the strategies in HEIs are formed in the face of environmental conditions and the choices that the leaders make to fulfill their purposes, since their performance has a strong relation with the administrative policies adopted, but mainly because of the implications that the strategic decisions adopted have contributed to its evolution.
\end{abstract}

Keywords: Strategy; Institution of higher education; LGB 9.394/96. 


\section{¿CÓMO OCURRE EL PROCESO DE FORMACIÓN DE ESTRATEGIAS EN INSTITUCIONES DE ENSEÑANZA SUPERIOR? - UN ESTUDIO EN SANTA CATARINA, BRASIL}

\section{RESUMEN}

El objetivo de este trabajo es conocer el proceso de formación de estrategia de las IES ubicadas en el Estado de Santa Catarina, bajo cuatro enfoques teóricos: proceso planificado, negociado, construcción permanente y de cambios, a partir de la introducción y repercusión de la LDB 9.394 / 96. En términos metodológicos, esta investigación asumió un enfoque cuantitativo, con el uso del método survey. En cuanto a la naturaleza se clasifica como descriptiva, exploratoria y explicativa. Se constituyó instrumento de recolección cuestionario compuesto por 41 cuestiones cerradas del tipo Likert de cinco puntos y dos cuadros asociativos para los respondedores numerar por orden de importancia las condicionantes para la formación de estrategias. Los cuestionarios fueron distribuidos durante el período de marzo y abril de 2011, a las 61 IES catarinenses, no obteniendo retorno de 20 instituciones. Los datos fueron tabulados y recibieron tratamiento estadístico a través del software Statistical Package for the Social Sciences - SPSS versión 20.0, haciendo uso de la estadística multivariada para fines de análisis. Los resultados se remontan a que el proceso de formación de estrategia está fuertemente influenciado por el ambiente de trabajo y las variables del ambiente general y que las IES perciben su estrategia como sostenida por el proceso planificado. Este estudio proporcionó una mejor comprensión de cómo las estrategias en IES se forman frente a las condiciones ambientales y las elecciones que los dirigentes hacen para cumplir sus propósitos, ya que el desempeño por ellas presentado tiene una fuerte relación con las políticas administrativas adoptadas, pero principalmente por las implicaciones que ellas las decisiones estratégicas adoptadas han contribuido a su evolución.

Palabras clave: Estrategia; Institución de Enseñanza Superior; LDB 9.394 / 96.

\footnotetext{
${ }^{1}$ Doutorando em Educação pelo Centro Universitário La Salle - UNILASALLE. Vice-reitor na Universidade do Oeste de Santa Catarina - UNOESC. Brasil. E-mail: ricardo.demarco@unoesc.edu.br

${ }^{2}$ Mestre em Administração pela Universidade do Oeste de Santa Catarina - UNOESC. Professor na Universidade Federal de Pelotas - UFPEL. Brasil. E-mail: glebersonsantana@hotmail.com

${ }^{3}$ Doutora em Administração e Turismo pela Universidade do Vale do Itajaí - UNIVALI. Professora do Doutorado Acadêmico em Administração e Mestrado Profissional em Administração da Universidade do Oeste de Santa Catarina UNOESC, e no mestrado acadêmico da Universidade do Sul de Santa Catarina - UNISUL. Brasil. E-mail: $\underline{\text { simone.sehnem@unoesc.edu.br }}$
} 


\section{INTRODUÇÃO}

A dinâmica e a velocidade cada vez maior das mudanças - sociais, econômicas e culturais -, da sociedade moderna, caracterizam um novo cenário para o ensino superior neste novo milênio. Trata-se de transformações globais e de mudanças significativas nos valores, crenças pessoais e culturais, que culminam na consolidação da chamada sociedade do conhecimento. Este contexto de significativas mudanças no cenário do ensino superior são constatações verificadas no trabalho de Colossi, Consentino \& Queiroz (2001).

De acordo com essa visão, Meyer \& Murphy (2000) destacam queo processo de globalização é dominante, indicando a formação de blocos econômicos, integração econômica e inovação tecnológica, influenciando diretamente os hábitos de consumo e do meio social.

Em meio a esse contexto, o desenvolvimento do ensino superior em escala internacional está correlacionado com a evolução da sociedade, influenciado em especial pelas áreas política, econômica, cultural e do contexto social. Essas influências, de acordo com Porto \& Régnier (2003), sugerem que a educação superior define um campo de atuação que guarda certa autonomia em relação aos demais, com suas idiossincrasias e suas relações de poder próprio. Nesse norte, há de se considerar a interferência dos vários setores da sociedade e das transformações que esse contexto global, dinâmico e competitivo impõe nessa área, elementos que estabelecem estreita relação com os movimentos de mudança no percurso evolutivo desse campo.

Tendo em vista as transformações globais, as Instituições de Ensino Superior - IES - caracterizam-se como instituições de séculos, que ao longo do processo evolutivo passaram a exercer significativa influência na formação do ser humano e, em consequência, da sociedade. Campos \& Verni (2006) enfatizam queas IES têm o papel fundamental de formar cidadãos críticos, desenvolvendo a inquietude social.

Diante do cenário de incertezas, principalmente a partir da implementação Lei de Diretrizes e Bases para Educação Nacional n. 9.394/96, muitas IES foram pressionadas à adequar-se ao contexto estratégico. Segundo a LDB as IES seriam classificadas de acordo com a sua organização acadêmica (definidas em Lei, Decreto n. 3860 de 9 de julho de 2001): universidades, centros universitários, faculdades integradas, institutos e escolas superiores e centros de educação tecnológica, sejam de caráter público ou privado. Dessa forma, questiona-se como acontece o processo de formação de estratégia nas IES? Em vista a responder a este questionamento, constituiu objetivo central o de conhecer como é o processo de formação de estratégia das IES localizadas no Estado de Santa Catarina, sob quatro enfoques teóricos: processo planejado, negociado, construção permanente e de mudanças, a partir da LDB 9.394/96.

Este trabalho se justifica pela necessidade de melhor compreender como as estratégias são formadas face às condições ambientais e as escolhas que os dirigentes fazem para cumprir seus propósitos. Especula-se que o desempenho apresentado hodiernamente tem forte relação com as políticas administrativas adotadas, mas principalmente pelas implicações que as decisões estratégicas adotadas têm contribuído para a sustentação de tal evolução.

Segundo Meyer \& Murphy (2000) as IES estão em um mercado instável e competitivo, qualificando-as metaforicamente de acordo com a falta habilidade aos dirigentes de IES para administrar as questões relacionadas à gestão empresarial e acadêmica, ou à maestria nesse processo. Diante de suas ações os autores as classificam como "dinossauros", "gazelas" ou "tigres" do ensino superior, seja por meio do retardo e lentidão que facilmente poderiam ser relacionados à figura dos extintos dinossauros, da inteligência e velocidade das gazelas, que em geral sabem o que querem e agem de forma rápida, ou da agressividade e perspicácia dos tigres que atacam por sua natureza, de forma planejada e voraz.

O quadro comparativo de Meyer \& Murphy (2000) retrata a complexidade e fragilidade nos modelos de gestão de IES, estimulando estudos vinculados a essa temática que possibilitem o melhor entendimento das alternativas de melhorar o desempenho deste tipo de organizações. Por consequência, este trabalho fornecerá contribuições no sentido de explicar a forma como os gestores decidem, ou são levados a decidir, sobre as estratégias.

A possibilidade de melhoria de desempenho das IES frente às mudanças às quais o setor está envolvido tem impactos na sociedade em geral, posto que as IES contribuem para o desenvolvimento socioeconômico das diversas regiões onde estão inseridas, formando um número significativo de profissionais de várias áreas do conhecimento para o mercado de trabalho, participando assim ativamente do desenvolvimento local e regional.

No campo científico, o presente trabalho contribui ainda com o desenvolvimento teórico acerca do tema formação de estratégias em IES. Além do mais, visa-se também a cooperar de maneira mais genérica para o estudo da gestão das organizações do setor de serviços de educação superior, verificando estratégias empreendidas ao longo do tempo, suas motivações, atores, catalisadores, elementos de dificuldades e resultados. Dessa forma, será facilitada para a comunidade acadêmica essa investigação que permitirá a compreensão teórica e prática dos fenômenos abordados, pois os dados que serão levantados e analisados retratam a prática deste fenômeno em uma amostragem intencional. Acreditase que este estudo oferecerá, também, subsídios que permitam monitorar sistematicamente o processo de 
formação de estratégias, facilitando, assim, a tomada de decisão.

Para desenvolver a argumentação proposta, além desta introdução estruturou-se o artigo em cinco tópicos, além do (1) atual que tratam das seguintes questões: (2) estratégia e contexto das IES brasileiras; (3) o percurso metodológico da pesquisa; (4) apresentação, análise e discussões dos dados e as (5) considerações finais do estudo.

\section{REFERENCIAL TEÓRICO}

\subsection{Processo de Formação de Estratégia}

Entre alguns conceitos de estratégia pode-se citar: de acordo com Ansoff (1965, p. 104) entende-se a estratégia de forma mais técnica, como sendo: "o negócio em que estamos; as tendências que se verificam; decisões heurísticas de primeira ordem; nicho competitivo; e características de portfólio". Porter (1996, p. 72) afirmam que a estratégia "é a escolha de uma posição única e valiosa baseada em sistemas de atividades que são difíceis de copiar e que agregam valor." Para Drucker (1954, p. 82), a estratégia pode ser vista "como novas combinações que visam explorar oportunidades novas e diferentes no futuro". Para Whittington (2004, p. 47), “a estratégia não é exclusivamente um atributo das organizações, mas é algo que as pessoas comumente praticam".

Dentre os muitos conceitos de estratégia, um dos mais utilizados é o de Wright, Kroll \& Parnell (1998, p. 74), que a definem como "planos da alta administração para alcançar resultados consistentes com a missão e os objetivos gerais da organização". Barney \& Hesterly (2006) também contribuem afirmando que, estratégia de uma empresa é definida como sua teoria de como obter vantagens competitivas.

Apesar do campo de "estratégia" ter o seu crescimento amplamente associado aos EUA, principalmente devido aos trabalhos de Frederick W. Taylor, a busca pela racionalização da produção e pela maior eficiência nos processos administrativos manifestou-se também na França através de Fayol em 1930, na Alemanha e no Reino Unido por meio de Kipping em 1997 e até no Brasil por meio de Vargas em 1985. (Conke, 2013).

Dentre os trabalhos mais conhecidos na área de estratégia se encontra os de Porter que, em 1985, propôs a análise da cadeia de valor buscando a compreensão de como uma empresa constrói a sua estratégia e a sua vantagem competitiva, sem perder o controle e a coerência da cadeia de valor (Carneiro, Cavalcanti, \& Silva, 1997). Ainda de acordo com Carneiro, Cavalcanti, \& Silva (1997), a pergunta básica que Porter se propõe a responder é: Por que as indústrias diferem quanto ao seu potencial de lucro? O modelo da cadeia de valor permite a divisão da empresa nas suas atividades de relevância estratégica, para a compreensão dos custos e das fontes existentes ou potenciais de diferenciação (Carneiro, Cavalcanti, \& Silva, 1997).

Já Mintzberg (2006), apresenta que a empresa desenvolve sua personalidade assim como os indivíduos desenvolvem seu caráter, interagindo com o ambiente externo e interno. $O$ autor defende a necessidade da definição mais completa do termo estratégia, baseado na complementaridade de cinco definições denominadas 5 P's da estratégia, pelo qual pode-se realizar o diagnóstico e levantar o perfil estratégico de uma organização (Mintzberg, 2006).

De acordo com Mintzberg (2006), os 5 P's, da Estratégia, originados em 1987, são: (i) estratégia como plano; (ii) estratégia como pretexto; (iii) estratégia como padrão; (iv) estratégia como posição; (v) estratégia por perspectiva.

Quanto ao processo de formação de estratégias, uma abordagem esclarecedora foi notada a partir da perspectiva teórica Mintzberg \& Quin (2001) sobre o "processo estratégico". Os autores destacam que o processo de formação de estratégias distancia-se de modelos prescritivos expressos em planos formais sustentados em análises criteriosas do ambiente e guiados por objetivos e metas, delineados por Chandler (1962), Ansoff (1965), Andrews (1971), Porter (1980, 1985) e Mintzberg (2006). De acordo com Mintzberg \& Quin (2001), o processo de formação de estratégias é sustentado por elementos que aproximam-se de padrões evolutivos de aprendizado e interação do estrategista com a organização, em um processo dinâmico que evolui ao longo do tempo, sem plano formal como guia.

A partir da verificação dos modos de formação de estratégia, pretende-se discutir os aspectos dos processos de criação de estratégias, consoante à classificação de Nicolau (2001), que apesar do grande número de abordagens sobre o tema, essa autora optou por três linhas: a formação de estratégia como processo formal; a formação da estratégia como processo negociado; e a formação da estratégia como processo de construção permanente. Por fim, apresenta-se, também, a formação de estratégia como processo de mudança.

a) A formação de estratégia como um processo planejado: formulação de estratégias: em conformidade com alguns dos principais pesquisadores acerca do planejamento estratégico como Ansoff (1965) e Porter (1980, 1985), as estratégias resultam de um processo controlado e consciente de planejamento formal, decomposto em elaborada sequência de etapas distintas, cada uma delineada por check lists e apoiada por técnicas estruturadas, a partir dos executivos, no topo da pirâmide organizacional. O entendimento é de que o planejamento 
estratégico, consolidado em um documento, proporciona uma estrutura unificada por meio da qual os gestores podem tratar os principais problemas da organização, identificar mais facilmente novas oportunidades, avaliar as forças que podem ser potencializadas e as fraquezas que devem ser corrigidas (Nicolau, 2001).

b) A formação da estratégia como um processo negociado: conforme ponderado por Nicolau (2001), apresenta as etapas dos processos decisórios organizacionais oriundos das teorias sobre decisão, encontradas, por exemplo, em Simon (1947, 1971), March \& Simon (1981), e outros. Para Simon (1971), o processo decisório pode ser pensado como composto de quatro fases distintas: 1. Inteligência; 2. Projeto; 3. Escolha; e 4. Implantação. Sem negar o processo formal, esse enfoque valoriza o processo de negociação a partir da concepção da empresa como um corpo social, de indivíduos que interagem politicamente (Nicolau, 2001). Pettigrew (1977) concorda com esta concepção, e defende que a formação da estratégia nas organizações é processo contínuo e eminentemente político. Segundo ele, as estratégias emanam do processo decisório e dos diversos eventos acerca dos dilemas organizacionais.

c) A formação da estratégia como um processo de construção permanente: formação de estratégias. Considerando as limitações das abordagens anteriores, Nicolau (2001, p.11) destaca que: [...] a formação da estratégia é um processo complexo e que as perspectivas anteriores não capturam todas as suas dimensões.
Enquanto o sistema de planejamento formal centra-se em fatores quantitativos, desvalorizando os aspectos qualitativos (comportamentais e organizacionais).

d) A formação da estratégia como um processo de mudanças: Mintzberg, Ahlstrand, Lampel (2000) observam que as mudanças trazem novas combinações de circunstâncias para a organização. Os autores destacam que as mudanças ocorrem nas organizações ao longo do tempo, como reação adaptativa de um processo fragmentado, no qual as decisões são tomadas, com pouca consideração sobre metas definidas ou plano previamente estruturado.

Ainda sobre o processo de formação ou formulação de estratégia, seu pressuposto implícito é que toda organização tem uma estratégia, ainda que nunca tenha sido formal e explicitamente concebida. (Rebelo, Coelho \& Erdmann, 2005). Essa visão está relacionada ao processo de planejamento formal ou de adaptação que a organização adota para responder às demandas e mudanças do ambiente. (Mintzberg \& Quinn, 2001). Trata-se do padrão formal ou que emerge na organização em resposta contínua ao ambiente, ao longo dos tempos.

Apesar ser um tema por demais debatido no meio acadêmico Pinto et al. (2016) o tema estratégia possui relevância em meio a complexidade do contexto em que as organizações estão inseridas. Além disso, é trazida uma perspectiva atual do campo, com assuntos mais contemporâneos e ligações com temáticas do campo de estudos organizacionais e que apesar do consenso ainda frágil e sofrendo forte influência da economia, seus estudos se sobrepõem aos de outros campos (Pinto et al., 2016). No Quadro 1 são apresentados estudos nacionais recentes sobre a temática Estratégia. 
Como Ocorre o Processo de Formação de Estratégias em Instituições de Ensino Superior? - Um Estudo em Santa Catarina

\begin{tabular}{|c|c|c|}
\hline AUTORES & ANO & OBJETIVO \\
\hline Brito \& Oliveira & 2016 & $\begin{array}{l}\text { Apresentar uma análise teórica e empírica da relação entre gestão de recursos } \\
\text { humanos }(\mathrm{GRH}) \text { e desempenho organizacional }\end{array}$ \\
\hline Oliveira Júnior et al. & 2016 & $\begin{array}{l}\text { Propor um modelo em que a OE está associada à AE, esta relação sendo } \\
\text { influenciada pelo antecessor (alta administração), e a OE atuando de forma } \\
\text { multidimensional. }\end{array}$ \\
\hline Cardoso \& Kato & 2015 & $\begin{array}{l}\text { Levantar arcabouço teórico de pesquisas acerca de capacidades dinâmicas } \\
\text { entre os anos de } 1992 \text { e } 2012 \text { em periódicos internacionais. }\end{array}$ \\
\hline Morais et al. & 2015 & $\begin{array}{l}\text { Propor e aplicar um método para avaliar a maturidade do processo de } \\
\text { cenários nas organizações. }\end{array}$ \\
\hline Aguiar \& Frezatti & 2014 & $\begin{array}{l}\text { Investigar o relacionamento entre o uso de medidas não financeiras de } \\
\text { desempenho e orientação temporal dos gestores ao examinar empiricamente } \\
\text { predições normativas da contabilidade no que se refere ao relacionamento } \\
\text { positivo entre o uso de medidas não financeiras de desempenho e orientação } \\
\text { temporal dos gestores. }\end{array}$ \\
\hline $\begin{array}{l}\text { Capalonga, Diehl \& } \\
\text { Zanini }\end{array}$ & 2014 & $\begin{array}{l}\text { Propor uma ferramenta que permita a identificação das abordagens } \\
\text { estratégicas das organizações. }\end{array}$ \\
\hline $\begin{array}{l}\text { Carvalho, Prévot \& } \\
\text { Machado }\end{array}$ & 2014 & $\begin{array}{l}\text { Levantar os recursos considerados estratégicos em propriedades rurais de } \\
\text { acordo com a teoria da Visão Baseada em Recurso. }\end{array}$ \\
\hline Facinelli \& Alberdi & 2014 & $\begin{array}{l}\text { Analisar a relação entre a integridade estrutural dos processos de IE e sua } \\
\text { dimensão estratégica em um grupo de } 44 \text { empresas que fazem parte de uma } \\
\text { grande cooperativa de empresas na Comunidade Autônoma do País Basco na } \\
\text { Espanha. }\end{array}$ \\
\hline $\begin{array}{l}\text { Faria, Imasato \& } \\
\text { Guedes }\end{array}$ & 2014 & $\begin{array}{l}\text { Discutir se a hegemonia euro-americana contemporânea em GE ajuda a } \\
\text { construir a autoridade legítima de estrategistas das grandes corporações, } \\
\text { tanto a invisibilizar estrategistas euro-americanos de Estado quanto a } \\
\text { deslegitimar estrategistas e organizações do resto do mundo que representam } \\
\text { outros tipos de capitalismo ou alternativas ao ocidentalismo histórico. }\end{array}$ \\
\hline Martins et al & 2014 & $\begin{array}{l}\text { Correlacionar o comportamento estratégico dos gestores das indústrias } \\
\text { vinícolas nacionais com o processo de ambidestria organizacional. }\end{array}$ \\
\hline $\begin{array}{l}\text { Miragaia, Ferreira \& } \\
\text { Carreira }\end{array}$ & 2014 & $\begin{array}{l}\text { Identificar e priorizar os stakeholders envolvidos na tomada de decisão de } \\
\text { uma organização desportiva. }\end{array}$ \\
\hline Rodrigues et al & 2014 & $\begin{array}{l}\text { Compreender como a indústria editorial brasileira está enfrentando essas } \\
\text { transformações, capazes de alterar profundamente seu modelo de negócios. }\end{array}$ \\
\hline
\end{tabular}

Quadro 1 - Estudos nacionais recentes sobre a temática estratégia Fonte: os autores (2017).

A estratégia, como apontado por diversos autores, atua como aglutinadora intelectual de diversas possibilidades de abordagens integradas, como a do presente estudo. Segundo a demonstração do Quadro 1, observa-se que o tema estratégia tem sido relacionado a diversas temáticas e contextos, processo de adaptação estratégica, formulação e proposição de ferramentas estratégicas, RBV e orientação estratégica.

Na busca por artigos recentes, dos últimos três anos (2014, 2015 e 2016) na base de dados de periódicos nacionais Spell classificados, segundo o QUALIS CAPES em A1, A2 e B1, onde filtrou-se a palavra-chave "estratégia", foram encontradas 12 (doze) publicações de uma série de 129 (cento e vinte e nove) artigos científicos de periódicos A1 a B5.

\subsection{Contexto das Instituições de Ensino Superior brasileiras}

Historicamente, a primeira universidade brasileira foi fundada em 1920, no Rio de Janeiro. A partir desse marco, Stallivieri (2003), ressalta alguns momentos importantes na história da educação de nível superior no Brasil.

Inicialmente, a ênfase era o ensino com forte orientação profissional disponível para a elite, com pouca ênfase na pesquisa; no período entre 1930 (revolução industrial) e 1964 (quando o governo militar assume o poder) foram criadas 20 universidades federais, com grande número de professores europeus. Nesse período, surgem as universidades religiosas (católicas e presbiterianas); em 1968, inicia o movimento da reforma universitária, que tinha como base a eficiência administrativa, estrutura departamental e a indissociabilidade do ensino, pesquisa e extensão. Na década de 70 , verificou-se a expansão dos cursos de pós-graduação e a possibilidade de intercâmbios para capacitação 
docente; a partir dos anos 90, uma nova fase com a Constituição de 1988 e com a homologação de leis que passaram a regular a educação superior, em razão da necessidade de flexibilização e ampliação do sistema, redução da influência do estado e melhoria da qualidade. (Stallivieri, 2003).

As mudanças verificadas desde a Constituição de 1988 consolidaram-se a partir de meados da década de 1990, momento em que se observou uma vertiginosa expansão da oferta de cursos no sistema de ensino superior brasileiro. De acordo com o Censo do Ensino Superior INEP/MEC de 2005, um aspecto que pode ter contribuído para esse crescimento foi a Lei de Diretrizes e Bases para a Educação Nacional n. 9.394/96, que flexibilizou a entrada e a expansão de novas Instituições de Ensino Superior (IES), especialmente as de caráter privado e fundacional, que já operavam no país. (Brasil, 2005).

Preceitua Stallivieri (2003), a LDB 9.394/96 estabeleceu que as IES seriam classificadas de acordo com a sua organização acadêmica (definidas em lei, Decreto n. 3860 de 9 de julho de 2001): universidades, centros universitários, faculdades integradas, institutos e escolas superiores e centros de educação tecnológica, sejam de caráter público ou privado. Em relação ao ensino privado, Steiner (2006) e Esteves (2007) distinguem dois tipos: as Instituições Privadas Comunitárias, que são instituições sem fins lucrativos, cujo patrimônio pertence às comunidades que as criaram e que devem investir em suas atividades todo o resultado da sua atividade educacional; e as Instituições Privadas Particulares, instituições com finalidades lucrativas, que possuem um ou mais proprietários, de caráter privado. Essa nova dinâmica organizacional contribuiu significativamente para o crescimento do número de IES no Brasil.

Santini et al. (2015) esclarece que todas as instituições de ensino superior são credenciadas, primeiramente, como faculdades. No caso do credenciamento de Universidade depende de alguns fatores qualitativos e algumas prerrogativas, como: possuir produção intelectual institucionalizada, mediante estudos sistemáticos de temas mais relevantes sob o ponto de visto científico e cultural; possuir no mínimo de um terço do corpo docente composto de mestres e doutores, inclusive em regime de tempo integral. Outra prerrogativa é a formação pluridisciplinar dos quadros profissionais de nível superior, de pesquisa, de extensão e de domínio e cultivo do saber humano. Além disso, a instituição precisa oferecer regularmente no mínimo $60 \%$ dos cursos de graduação reconhecidos ou em processo de reconhecimento pelo MEC, oferta de quatro cursos de mestrado e dois de doutorado com reconhecimento legal.

Segundo os dados do Censo do Ensino Superior INEP/MEC de 2005, o Brasil contava em 1995 com 894 IES, sendo 210 de cunho público e 684 privadas. Em 2005, o número aumentou para 2.165
IES, sendo 231 públicas e 1.934 privadas. Ou seja, enquanto o número de IES públicas aumentou 10\%, o setor privado aumentou sua participação em $116 \%$. Conforme Esteves (2007), essa forte expansão do número de organizações aumentou a competição entre as IES de ensino privado no Brasil em um segmento marcado até então por um ambiente de estabilidade e baixa concorrência. Consoante o autor, havia clara demanda reprimida que justificava tal crescimento.

Entretanto, números do Censo do Ensino Superior INEP/MEC de 2008 demonstram comportamento diferente: no ano de 2008, por exemplo, houve uma diminuição de 29 IES em relação ao ano de 2007, passando de 2.225 IES em 2007 para 2.196 IES em 2008. Tal diminuição pode ser explicada pela integração de instituições, por fusão ou compra, observada nos últimos anos. Cabe ressaltar, contudo, que a variação no número de IES dos últimos anos não se refletiu na oferta de vagas. De acordo com o Censo de 2008, o número total de vagas ofertadas em 2008 foi de 2.985.137, o que correspondeu a um incremento de $161.195(5,7 \%)$ em relação ao ano anterior. (BRASIL, 2008).

Em meio a esse contexto, o desenvolvimento do ensino superior está correlacionado com a evolução da sociedade, influenciado em especial pelas áreas política, econômica, cultural e do contexto social. Essas influências, de acordo com Porto \& Régnier (2003), sugerem que a educação superior define um campo de atuação que guarda certa autonomia em relação aos demais, com suas idiossincrasias e suas relações de poder próprio. Nesse norte, há de se considerar a interferência dos vários setores da sociedade e das transformações que esse contexto global, dinâmico e competitivo impõe nessa área, elementos que estabelecem estreita relação com os movimentos de mudança no percurso evolutivo desse campo.

Tendo em vista as transformações globais, as IES caracterizam-se como instituições de séculos, que ao longo do processo evolutivo passaram a exercer significativa influência na formação do ser humano e, em consequência, da sociedade. Campos \& Verni (2006) enfatizam que, na sociedade atual, as IES têm o papel fundamental de formar cidadãos críticos, desenvolvendo a inquietude social.

Nessa nova dinâmica, um dos fatos notórios refere-se à expansão do acesso ao ensino superior ao longo das últimas décadas. Para Vahl, Meyer \& Finger (1989), a ampliação do acesso ao ensino superior revelou a existência de demanda além da capacidade de atendimento, abrindo espaço para uma nova arena no campo do ensino superior e, dessa forma, observa-se a inserção de novas instituições dos tipos mais diversos com vistas a ocupar as oportunidades abertas. Muitas são as instituições públicas, sem fins lucrativos ou com propósitos filantrópicos. Outras, no entanto, são instituições criadas por empreendedores que visam a 
obter lucros e que são geridas segundo os métodos e práticas típicos de empresas ou de mercado.

Porto \& Régnier (2003) demonstram no Quadro 02 que as principais tendências e forças de mudanças para o ensino superior, em termos mundiais, se darão em torno (1) da introdução de novos elementos; (2) novos protagonistas; (3) nas relações da universidade com a sociedade; (4) na prestação de serviços; e (5) no modo de execução das atividades acadêmicas.

\begin{tabular}{|c|c|}
\hline TENDÊNCIAS & $\begin{array}{l}\text { FATORES DE MUDANÇA } \\
\text { (CONTINUA) }\end{array}$ \\
\hline $\begin{array}{l}\text { 1. Mudança nas } \\
\text { características do setor de } \\
\text { educação superior por } \\
\text { meio da introdução de } \\
\text { novos elementos. }\end{array}$ & $\begin{array}{l}\text { - Quebra do monopólio geográfico, regional ou local. } \\
\text { - Ambiente globalizado, altamente competitivo e cada vez mais } \\
\text { desregulamentado. } \\
\text { - Instituições especializadas e centradas no aluno (e não no professor). } \\
\text { - Significativa reestruturação, implicando no desaparecimento e fusão de } \\
\text { universidades. }\end{array}$ \\
\hline $\begin{array}{l}\text { 2. Mudança na estrutura do } \\
\text { setor de } \\
\text { superior. }\end{array}$ & $\begin{array}{l}\text { - Universidades corporativas patrocinadas ou administradas por grandes } \\
\text { empresas. } \\
\text { - Empresas instrucionais - instituições terceirizadas que prestam serviços às } \\
\text { universidades. } \\
\text { - Entidades de intermediação, cuja função é fazer a ponte entre os } \\
\text { provedores de educação superior e os consumidores. } \\
\text { - Empresas de telecomunicação, de informática e de informação, de } \\
\text { entretenimento, bem como organizações governamentais e do terceiro setor } \\
\text { engajadas na educação, treinamento e desenvolvimento profissional. }\end{array}$ \\
\hline $\begin{array}{l}\text { 3. Mudança nas relações da } \\
\text { universidade com a } \\
\text { sociedade. Além dos } \\
\text { papéis clássicos do ensino, } \\
\text { pesquisa e extensão. }\end{array}$ & $\begin{array}{l}\text { - Os princípios estarão em consonância com os interesses da sociedade } \\
\text { (serviços de saúde e de assistência, desenvolvimento econômico, } \\
\text { entretenimento, etc.). }\end{array}$ \\
\hline $\begin{array}{l}\text { 4. Mudança na natureza da } \\
\text { prestação dos serviços } \\
\text { acadêmicos. }\end{array}$ & $\begin{array}{l}\text { - Foco na aprendizagem continuada. } \\
\text { - Atividades acadêmicas, inter-relacionadas. } \\
\text { - Aprendizagem assíncrona (qualquer tempo, qualquer lugar). } \\
\text { - Serviços diversificados, para atender às variadas necessidades e objetivos } \\
\text { da população. }\end{array}$ \\
\hline $\begin{array}{l}\text { 5. Mudança no modo de } \\
\text { execução das atividades } \\
\text { acadêmicas }\end{array}$ & $\begin{array}{l}\text { - A universidade prestadora de serviços do conhecimento (criação, } \\
\text { preservação, integração, transmissão e aplicação). } \\
\text { - Modelo produtivo próximo à produção em massa e com fortes influências } \\
\text { do modelo adotado na indústria de entretenimento. } \\
\text { - Os métodos de ensino-aprendizagem e os papéis dos professores serão } \\
\text { submetidos a fortes pressões para mudança, principalmente em função das } \\
\text { novas tecnologias da teleinformática e do surgimento de uma geração } \\
\text { digital. } \\
\text { - Em razão da tecnologia, a pesquisa e os processos de criação tornar-se-ão } \\
\text { muito mais coletivos e multidisciplinares. } \\
\text { - A biblioteca será suportada por diferentes mídias. } \\
\text { - No campo da extensão, a aplicação dos conhecimentos continuará a ser } \\
\text { ditada, cada vez mais, pelas necessidades e demandas reais da sociedade. }\end{array}$ \\
\hline
\end{tabular}

Quadro 2 - Tendências de forças de mudanças para o ensino superior Fonte: Porto \& Régnier (2003, p.19-20).

Esteves (2007) corrobora as tendências de mudanças relacionadas por Porto \& Régnier (2003) no Quadro 2, e destaca que a intensificação da competição, o surgimento da indústria do conhecimento, a desverticalização das IES e a formação de parcerias constituem as principais mudanças no setor.
Nesse sentido, Sampaio \& Laniado (2009) asseveram que este cenário de significativas mudanças assola as IES públicas, sem fins lucrativos, filantrópicas e de caráter particular com fins lucrativos. Acrescentam que as IES, independente do seu caráter constitutivo, estão sendo pressionadas essencialmente pelas práticas obsoletas de gestão, especificamente pela 
incapacidade de inovar e pela forma como trabalham suas estratégias ao longo do tempo. (Sampaio \& Laniado, 2009).

Diante do que foi discorrido, o contexto econômico, político, social e de administração em que as IES estão submetidas, de modo geral apresenta mudanças significativas, principalmente pelo aumento considerável do número de IES, num cenário de competição. Esses fatos podem indicar, na trajetória das IES, comportamento distinto no que se refere às decisões estratégicas, por consequência, na maneira como as estratégias são formadas.

\subsection{Estratégia e Instituições de Ensino Superior}

As instituições de ensino superior possuem impacto direto no desenvolvimento econômico local e no desenvolvimento social de regiões. Seus resultados são almejados por empresas, governo e sociedade. Demandam de ferramentas de gestão adequadas para se manterem competitivas. A formulação de estratégias e modelos de gestão também é um elemento essencial para o êxito das instituições de ensino superior (Enslinn et al, 2016).

Dados veiculados pelo Instituto Nacional de Estudos e Pesquisas Educacionais Anísio Teixeira Inep evidenciam que o Brasil passou por uma mudança na Educação Superior a partir dos anos 90, quando a Lei de Diretrizes e Bases da Educação flexibilizou a entrada de iniciativas privadas neste setor. A partir desse momento, a descentralização do ensino superior, em especial para regiões interioranas se tornou realidade, Os dados mostram que o país passou de 894 Instituições de Ensino Superior (IES) em 1995 para 2.416 em 2012. Ressalta-se que das 2.416 IES, 2.112 são instituições privadas (Brasil, Inep, 2014; Lima, et al, 2016).

Esse cenário estimula as instituições de ensino superior a desenvolverem novas estratégias de gestão, novas formas de interagir com os alunos e inovações para atrair estudantes para os espaços de ensino públicos e privados, A competitividade das IES privadas está associada as suas estratégias de gerenciamento de receitas e sua disseminação e operacionalização pelos gestores da organização. Desse modo, torna-se fundamental para o sucesso da IES que estas sejam entendidas e mensuradas em forma inteligível e não ambígua para permitir o seu contínuo monitoramento e aperfeiçoamento (Lima et al, 2016).

Sobretudo, porque de acordo com a Lei n. 9.394/1996, que estabelece as Diretrizes e Bases da Educação Nacional (LDB), as instituições de ensino superior (IES) objetivam "formar diplomados nas diferentes áreas do conhecimento, aptos para inserção em setores profissionais e para a participação no desenvolvimento da sociedade brasileira”, colaborando ainda na sua formação contínua. $\mathrm{O}$ conhecimento ser a principal input (entrada) e output (saída) nessas instituições (Córcoles, Ponce, 2013).

Montenegro e Bulgacov (2015) asseveram que as relações formadas entre os atores envolvidos na governança de instituições de ensino superior e seus efeitos sobre os seus resultados estratégicos por meio da análise da formação e da dissolução das redes de governança são aspectos importantes para a compreensão das organizações.

Outro aspecto a ser considerado no contexto das instituições de ensino superior são os resultados estratégicos, que correspondem aos resultados das atividades e das práticas estratégicas realizadas no cotidiano das organizações. Esses resultados podem ser tangíveis ou intangíveis, e podem contemplar duas dimensões: os resultados almejados e os resultados realizados. A escolha do conjunto de ações articuladas que visam a concretizá-los depende da sua definição e monitoração (Pereira \& Santos, 2001; Montenegro; Bulgacov, 2015).

Os resultados alusivos à qualidade de ensino, ao desenvolvimento de atividades pedagógicas e administrativas, à formação e preparação do corpo docente, à imagem da instituição e às condições de infraestrutura das IES são elementos relevantes no contexto das IES (Montenegro; Bulgacov, 2015).Uma estratégia organizacional é similar a um artefato tecnológico ou a uma descoberta científica. Assim, uma estratégia específica precisa ser factível para a rede de atores organizacionais (humanos e não humanos) que a apoiam. Portanto, o processo de fazer estratégia torna-se um processo de translação com todos os elementos potenciais previstos em um processo de translação: problematização; interesse; inscrição e mobilização, levando potencialmente (mas não de forma determinística) para a irreversibilidade de uma estratégia bem-definida (Denis, Langley, \& Rouleau, 2007; Montenegro; Bulgacov, 2015). 


\section{METODOLOGIA}

Metodologicamente, este estudo caracteriza-se quanto à abordagem como quantitativo, cuja natureza se classifica como descritiva, exploratória e explicativa. Descritiva porque está focado na compreensão do fenômeno sob investigação conforme conceitos e construtos teóricos (Roesch, 1999), cujo objetivo é o de desvendar e observar fenômenos, procurando descrevê-los, classificá-los e interpretálos, com o intuito de conhecer a sua natureza, sua composição, processos que o constituem ou nele se realizam. (Rudio, 1986). Essa visão é consoante à definição de Collis \& Hussey (2005, p.24) sobre pesquisa descritiva: "[...] é a pesquisa que descreve o comportamento dos fenômenos. É usada para identificar e obter informações sobre características de determinado problema ou questão".

A pesquisa também assumiu caráter exploratório porque foi realizada em área na qual há pouco conhecimento acumulado e sistematizado, onde se busca informações sobre um problema ou questão de pesquisa (Vergara, 1998, Collis \& Hussey, 2005)

Além disso, a pesquisa se caracterizou como explicativo, uma vez que, em conformidade com Andrade (2002), este tipo de pesquisa além de ser complexa procura identificar seus fatores determinantes por meio do registro, análise, classificação e interpretação dos fenômenos estudados. "A pesquisa explicativa tem por objetivo aprofundar o conhecimento da realidade, procurando a razão, o porquê das coisas e por esse motivo está mais sujeita a erros" (Andrade, 2002, p.20).

Salienta-se ainda que a opção pelo método quantitativo se justifica por permitir a verificação dos dados de forma transparente e precisa. Por conseguinte, esta pesquisa assumiu o método indutivo de análise, vez que "parte de elementos individuais para tirar conclusões e generalizações, relacionadas a uma amostra representativa, assegura a possibilidade de generalização dos resultados na pesquisa quantitativa" (Vergara, 1998, p.43).

Ainda segundo ao método, foi utilizado o survey que é caracterizado pelo questionamento da realidade, dos fenômenos e da população estudada, cujo comportamento se quer conhecer (Hair Jr et al., 2005), sendo, portanto, apropriada quando, segundo Vergara (1998, p.78):

- se deseja responder questões do tipo "o quê?, “"por quê?", "como" e "quando"?, ou seja, quando o foco de interesse é sobre "o que está acontecendo" ou "como e porque isso está acontecendo";

- não se tem interesse ou não é possível controlar as variáveis dependentes e independentes;

- o ambiente natural é a melhor situação para estudar o fenômeno de interesse;

- o objeto de interesse ocorre no presente ou no passado recente.

Os objetos de estudo da pesquisa foram Instituições de Ensino Superior (HEI) localizadas no Estado de Santa Catarina, Brasil. Foram pesquisados 41 IES de um universo de 61, de acordo com INEP (2011), ACAFE (2011) e AMPESC (2011), conforme demonstrado no Tabela 1.

Tabela 1 - Classificação das IES de acordo com a organização acadêmica

\begin{tabular}{|l|c|c|}
\hline Classificação de acordo com a organização acadêmica & $\begin{array}{c}\text { Número de IES em } \\
\text { Santa Catarina }\end{array}$ & $\begin{array}{c}\text { Número de IES que } \\
\text { retornaram }\end{array}$ \\
\hline $\begin{array}{l}\text { Faculdades Integradas, Institutos e Escolas Superiores e } \\
\text { Centros de Educação Tecnológica - Privadas }\end{array}$ & 43 & 28 \\
\hline Universidades e Centros Universitários - Comunitárias & 15 & 11 \\
\hline Universidades Públicas & 03 & 02 \\
\hline Total & $\mathbf{6 1}$ & $\mathbf{4 1}$ \\
\hline
\end{tabular}

Fonte: INEP (2011); ACAFE (2011); AMPESC (2011).

Constituiu instrumento de coleta questionário composto por 41 questões fechadas e objetivas do tipo Likert de cinco pontos e dois quadros associativos para os respondentes numerarem por ordem de importância as condicionantes para a formação de estratégias. As assertivas que compuseram o questionário foram extraídas da literatura convergente. Apesar do processo de elaboração próprio do instrumento de coleta de dados ser uma fragilidade para o estudo, permitiu a elaboração considerando a realidade do ensino superior no Brasil, onde há diversas especificidades que são próprias do nossa país e não são encontradas na realidade americana e européia, - regiões que lideram as pesquisas sobre a temática estratégia em nível de mundo. 
Como procedimentos foram utilizados os seguintes critérios:

- $\quad$ o instrumento foi aplicado por e-mail diretamente aos indivíduos da amostra;

- foi efetuado contato telefônico com todos os respondentes;

- os respondentes caracterizam-se como os dirigentes principais das IES - Presidente da Fundação Mantenedora, Reitor, Vice-reitores de Campus, Diretores ligados ao nível estratégico e Sócio-proprietário;

- no pré-teste efetuado com 5 (cinco) dirigentes da Unoesc Campus de Xanxerê o tempo de duração para responder os questionários ficou entre 8 min. e 12 min.;

- todos os questionários foram tabulados individualmente e tiveram tratamento estatístico.
Os questionários foram distribuídos as 61 IES, não obtendo retorno de 20 instituições que alegaram não divulgar as estratégias e a forma como procedem, em razão da concorrência ou simplesmente não terem o hábito de responder questões relacionados às estratégias (8) e outras IES (12) simplesmente não justificou a não-resposta.

O questionário foi aplicado durante o período dos meses de março e abril de 2011, tendo como respondentes, os informantes chaves das IES, intitulados por sua função diretiva: Presidente da Fundação Mantenedora, Reitor, Vice-reitores de Campus, Diretores ligados ao nível estratégico e Sócio-proprietário.

Além disso, afim de validar o instrumento de coleta de dados foi realizado pré-teste com 5 dirigentes da UNOESC Campus de Xanxerê/SC, por caráter de conveniência dos autores e relação estreita com a instituição. O tempo de reposta do questionário foi mensurado entre 8 minutos e 12 minutos. $O$ roteiro metodológico está apresentado na Tabela 2.

Tabela 2 - Metodologia e características do trabalho

\begin{tabular}{|c|c|c|c|c|}
\hline $\begin{array}{c}\text { Objetivos da } \\
\text { pesquisa }\end{array}$ & Hipóteses & $\begin{array}{c}\text { Aspectos } \\
\text { abordados }\end{array}$ & $\begin{array}{l}\begin{array}{l}\text { Sistematização da } \\
\text { informação }\end{array} \\
\end{array}$ & $\begin{array}{c}\text { Bases constitutivas } \\
\text { para análise }\end{array}$ \\
\hline $\begin{array}{l}\text { Verificar o nível de } \\
\text { formalidade } \\
\text { envolvido no } \\
\text { processo de } \\
\text { formação de } \\
\text { estratégias. }\end{array}$ & $\begin{array}{l}\text { H1: As estratégias } \\
\text { são parcialmente } \\
\text { planejadas e } \\
\text { parcialmente não } \\
\text { planejadas. }\end{array}$ & $\begin{array}{l}\text { Planejamento } \\
\text { formal, modos e } \\
\text { estilos de formação } \\
\text { de estratégias }\end{array}$ & Tabelas e gráficos & $\begin{array}{c}\text { Ansoff (1965); } \\
\text { Andrews (1971); } \\
\text { Miles \& Snow } \\
\text { (1978); } \\
\text { Porter (1980); } \\
\text { Mintzberg, } \\
\text { Ahlstrand \& } \\
\text { Lampel (2000) }\end{array}$ \\
\hline $\begin{array}{c}\text { Identificar o grau } \\
\text { de adequação do } \\
\text { processo } \\
\text { estratégico, como } \\
\text { processo negociado } \\
\text { para atender aos } \\
\text { interesses dos } \\
\text { diferentes grupos } \\
\text { internos }\end{array}$ & $\begin{array}{l}\text { H2: O processo de } \\
\text { formação de } \\
\text { estratégias é } \\
\text { predominantemente } \\
\text { oriundo de } \\
\text { comportamentos } \\
\text { irracionais }\end{array}$ & $\begin{array}{c}\text { O estilos de } \\
\text { formação de } \\
\text { estratégia, as escolas } \\
\text { de estratégia }\end{array}$ & Tabelas e gráficos & $\begin{array}{l}\text { Indenburg (1993); } \\
\text { Mintzberg, } \\
\text { Ahlstrand \& } \\
\text { Lampel (2000) }\end{array}$ \\
\hline $\begin{array}{c}\text { Averiguar a } \\
\text { existência de } \\
\text { padrões que } \\
\text { definam o processo } \\
\text { estratégico como } \\
\text { uma construção } \\
\text { permanente }\end{array}$ & $\begin{array}{l}\text { H3: As estratégias } \\
\text { surgem do processo } \\
\text { interativo dos } \\
\text { indivíduos } \\
\text { interessados }\end{array}$ & $\begin{array}{c}\text { Modos de formação } \\
\text { de estratégias, estilos } \\
\text { de estratégias e } \\
\text { estratégia como } \\
\text { prática }\end{array}$ & Tabelas e gráficos & $\begin{array}{c}\text { Mintzberg (1973); } \\
\text { Indenburg (1993); } \\
\text { Mintzberg, } \\
\text { Ahlstrand \& } \\
\text { Lampel (2000); } \\
\text { Whittngton (2002). }\end{array}$ \\
\hline $\begin{array}{c}\text { Examinar a } \\
\text { influência dos } \\
\text { fatores de mudança } \\
\text { do contexto externo } \\
\text { no processo de } \\
\text { formação de } \\
\text { estratégias }\end{array}$ & $\begin{array}{l}\text { H4: O processo de } \\
\text { formação de } \\
\text { estratégias é } \\
\text { extremamente } \\
\text { influenciado pelo } \\
\text { contexto ambiental, } \\
\text { sugerindo um }\end{array}$ & $\begin{array}{l}\text { Modos de formação } \\
\text { de estratégias, estilos } \\
\text { de formação de } \\
\text { estratégia, teorias } \\
\text { deterministas e } \\
\text { voluntaristas e teoria } \\
\text { institucional }\end{array}$ & Tabelas e gráficos & $\begin{array}{l}\text { Mintzberg (1973); } \\
\text { Idenburg (1993); } \\
\text { Mintzberg; } \\
\text { Ahlstrand e Lampel } \\
\text { (2000) }\end{array}$ \\
\hline
\end{tabular}




\begin{tabular}{|c|c|c|c|c|}
\hline & $\begin{array}{l}\text { comportamento } \\
\text { reativo }\end{array}$ & & & \\
\hline $\begin{array}{c}\text { Identificar os } \\
\text { condicionantes do } \\
\text { contexto, principais } \\
\text { stakeholders em } \\
\text { que são construídas } \\
\text { as estratégias }\end{array}$ & $\begin{array}{c}\text { H5: Os stakeholders } \\
\text { têm elevada } \\
\text { influência no } \\
\text { processo de } \\
\text { formação de } \\
\text { estratégias das IES. }\end{array}$ & $\begin{array}{c}\text { Ambiente tarefa, } \\
\text { ambiente geral e } \\
\text { ambiente } \\
\text { internacional ou } \\
\text { global }\end{array}$ & Tabelas e gráficos & Hatch (1997); \\
\hline
\end{tabular}

Fonte: os autores (2011).

Dessa forma, a partir dos objetivos propostos e das hipóteses elencadas foi elaborado e aplicado o questionário, tendo como basilares estudos clássicos da área de estratégia. Os resultados passaram por testes estatístico, afim de garantir confiabilidade: alfa de Cronbach, teste de normalidade, teste Chi-Square. Salienta-se que foi realizada análise estatística multivariada, aplicando análise fatorial dos indicadores, análise de cluster e análise multidimensional. Destaca-se que para análise dos dados recorreu-se ao uso do software estatístico Statistical Package for the Social Sciences - SPSS versão 20.0 .

\section{ANÁLISE DOS RESULTADOS}

Foram analisados 41 indicadores, formulados a partir de pressupostos teóricos da área de estratégia, organizados em quatro grupos e blocos que expliquem o processo real de formação de estratégia nas IES de Santa Catarina, sob o prisma: (1) processo planejado, (2) negociado, (3) construção permanente e de (4) mudanças.

\subsection{Processo Planejado de Formação de Estratégia}

A análise estatística do grupo de indicadores do processo planejado de formação de estratégias demonstrou que as variáveis que norteiam esta perspectiva teórica foram confirmadas pelos respondentes. $\mathrm{O}$ grupo apresentou índice de confiabilidade de $72 \%$, nível de significância de 0,520. Dos seis indicadores do grupo apenas um (X19), que versava "Avaliamos racionalmente nosso ambiente: interno (forças e fraquezas) e externo (oportunidades e ameaças) antes de definir as estratégias. Exemplo: análise de concorrentes, mercado, etc." obteve carga fatorial 0,297, ficando abaixo do mínimo aceitável $(0,5)$. Evidencia-se por este indicador isoladamente, que as IES respondentes tendem a não considerar o contexto ambiental em seu processo estratégico, contrariando a visão estrutural de Steiner (1969) e Mintzberg (1973) e a preocupação da análise ambiental de Andrews (1971) para o processo planejado de formação de estratégias.
Já os demais indicadores desse grupo apresentaram as maiores cargas fatoriais: X20 (As estratégias de nossa IES são decididas em um processo de Planejamento Estratégico, 0,828); X5 (Mensuramos as possibilidades de retorno das estratégias escolhidas a curto, médio e longo prazo, 0,776); X6 (Temos planos operacionais detalhados para implementar as estratégias, 0,726); X11 (Temos cronogramas definidos para a implementação prática das estratégias, com atividades, prazos e responsáveis pela execução, 0,637); X21 (Temos objetivos e metas estratégicos bem definidos, 0,570).

A avaliação positiva dos respondentes em relação a este grupo/bloco de indicadores está de acordo com a visão de que o processo de formação de estratégias consiste num processo controlado e consciente, decomposto em etapas distintas que apoiam a tomada de decisão dos executivos no topo da pirâmide organizacional, concepção com origens no tradicional planejamento estratégico.

Outra constatação é que as IES, ao acenarem positivamente ao processo planejado, apresentam forte relação com a intenção de antecipação dos acontecimentos do ambiente para garantir a maximização de resultados a curto, médio e longo prazo. (Ansoff, 1990). Nesse enfoque evidencia-se a postura formal e analítica dos dirigentes das IES, condição que limita o conhecimento sistêmico organizacional, visto que está ligado preferencialmente na análise, operacionalização e controle de metas e objetivos pré-estabelecidos. (Mintzberg, Ahlstrand, \& Lampel, 2000).

Esse comportamento deliberado de construção de estratégias nas IES de Santa Catarina é consoante com a visão de Rebelo; Coelho \& Erdmann (2005), em que este processo ocorre quando, primeiro se pensa depois, se age; quando primeiro se formula, para depois se implementar.

As análises demonstraram que nessa perspectiva a estratégia é criada, mediante processo formal, linear e analítico, pelo líder ou por um grupo, na cúpula da IES, tendo em vista o estabelecimento de objetivos e a definição de planos para atingi-los, consoante à visão de Mintzberg (1973); Mintzberg e Quin (2001). 
Deste modo, percebe-se que as IES de Santa Catariana orientam-se, pela perspectiva de processo prescritivo, deliberado, antecipado ou de 'formulação de estratégia', conforme postula Mintzberg (2004). Predomina a visão baseada na análise do ambiente, voltada para o desenvolvimento de estratégias para atingir objetivos traçados. (Idenburg, 1993).

\subsection{Processo Negociado de Formação de Estratégia}

Nesse grupo formado por cinco indicadores, o teste Alpha de Cronbach foi de 9,3\%, apresentando fraca relação com o processo de formação de estratégia das IES pesquisadas. Quanto ao teste de homogeneidade, este apresentou nível de significância abaixo do estabelecido $(0,5)$ alcançando índice de 0,458 . $\mathrm{Na}$ análise fatorial, o único indicador que apresentou carga positiva foi X8 que trata de "Nossos dirigentes determinam nossa estratégia".

Os demais indicadores que compunham o grupo apresentaram fraca carga fatorial: X18 (Os interesses de um grupo de pessoas em particular dão o "tom" das estratégias, 0,327); X9 (As estratégias são definidas de tal forma a acomodar os diferentes interesses de pessoas e grupos internos, como departamentos, áreas, gerentes, etc, 0,172); X13 (As estratégias têm constante interferência de grupos externos a IES, 0,078) e X24 (As estratégias têm de ser alteradas porque algum grupo dificulta sua implementação, -0,191).

As IES pesquisadas ao não assumirem a posição negociada em seu processo estratégico, indicam que pode estar ocorrendo a influência impositiva de seus dirigentes no processo de construção das estratégias, elementos previstos por Simon (1971); March \& Simon (1981) e destacado por Mintzberg, Ahlstrand \& Lampel (2000, p.174) como "[...] um processo aberto de influência, enfatizando o uso de poder e política para negociar estratégias favoráveis a determinados interesses [...]", consideração verificada afirmativamente no indicador "8 - Nossos dirigentes determinam nossa estratégia".

Esta condição formal e centralizada vai de encontro aos argumentos de Cyert \& March (1963), em que a formação de estratégia é mais que um esforço controlado de análise e decisão entre alternativas, que busca compreender o ambiente em toda sua complexidade, elencando as possibilidades de escolhas para escolher o melhor caminho.

Resta evidente: as IES pesquisadas, ao desconsiderar em seu processo estratégico que "9 - As estratégias são definidas de tal forma a acomodar os diferentes interesses de pessoas e grupos internos (departamentos, áreas, gerentes, etc)", acenam para a desconsideração da pluralidade de interesses existentes entre os indivíduos e grupos que se relacionam com a organização. (Cyert \& March, 1963, Murray, 1978).

\subsection{Processo de Construção Permanente de Formação de Estratégia}

Este grupo apresentou índice de confiabilidade, de acordo com o teste Alplha de Cronbach de 30,9\%, demonstrando fraca relação com o processo de construção permanente de estratégia. Quanto ao teste de homogeneidade, este obteve nível de significância próximo do estabelecido $(0,5)$ com índice de 0,499 .

Tangenciando sobre a análise fatorial dos 9 indicadores, três apresentaram carga significativa, foram: X14 (As estratégias de nossa IES são continuidade dos padrões de ação do passado, com carga fatorial de 0,722); X15 (Nossas estratégias são o reflexo da reação as dificuldades impostas pelo ambiente, 0,687) e X25 (À época da adoção da estratégia, as opções estratégias eram limitadas, portanto, pode-se dizer que a alternativa adotada praticamente se impôs, 0,604).

Os demais indicadores que tiveram resultado majorado a $0,431,0,325,-0,229,-0,294,-0,359$, 0,556 , respectivamente, versavam sobre X17 "Nossas estratégias refletem 'o jeito que fazemos as coisas aqui", X7 "É difícil dizer como surgiu a ideia que afinal gerou a estratégia", X1 "Nossas estratégias são de fato o que as pessoas fazem", X26 "Criatividade e intuição foram essenciais na formulação da estratégia”, X22 “Os valores culturais são levados em consideração nas definições da estratégia" e X3 "Nossas estratégias são oriundas do processo criativo pessoal e visionário dos nossos dirigentes".

A concepção teórica do processo de construção permanente de formação de estratégias proposta por Nicolau (2001) relaciona-se com a lição de Mintzberg (1978) de estratégias emergente, que são aquelas que surgem sem que haja intenção definida, tendo como principal característica a sua base em um processo de tentativa e erro. Consoante a esses autores, trata-se da estratégia não planejada, oriunda do processo criativo.

Essa análise demonstra que as IES pesquisadas distanciam-se da perspectiva emergente de formação de estratégias, elemento fundamental do processo de construção permanente de formação de estratégias. Isso em razão das evidências demonstradas pela análise multivariada que aspectos que caracterizam esta perspectiva, delineadas inicialmente por Mintzberg (1978), como variáveis psicossociológicos, valores culturais, criatividade, intuição e visão do estrategista não se confirmaram.

Outros elementos vinculados à interação sociológica do estrategista ao processo estratégico verificados em Whittington (1993) e Rebelo, Coelho \& Erdmann (2005), como pensar e agir, planejar e executar; e a interação da idealização, construção e 
efetivação das estratégias, não foram confirmadas pelo grupo/bloco de indicadores analisados.

\subsection{Processo de Mudanças de Formação de Estratégia}

Esse grupo apresentou confiabilidade, segundo o Alpha de Cronbach de 30,9\%, o que evidencia baixa relação $\mathrm{cm}$ o processo de formação de estratégias das IES pesquisadas. Segundo o teste de homogeneidade por meio do teste de Bartlett sugerido por Maroco (2010), a análise apresentou índice de 0,435, ficando abaixo do estabelecido.

Do conjunto de seis indicadores, apresentaram as maiores cargas fatoriais: X10 "Não temos como mudar nosso ambiente de negócios, somos conduzidos pelo mercado", com 0,877 e X12 "Nossa liberdade para fazer escolhas é restringida porque o ambiente externo à empresa (mercado, concorrência, governo, etc.) determina as direções", com 0,775.

Os demais indicadores apresentaram baixa carga fatorial, respectivamente: X23 "As regras do nosso mercado têm se mantido estáveis", 0,381; X16 "A maioria das mudanças estratégicas em nossa IES ocorre por forças externas", 0,240; X4 "No nosso ramo de atividade, as mudanças são freqüentes e exigem constante atualização", 0,152, e X2 "Para mantermo-nos alinhados ao nosso ambiente mudamos nossa estratégia", $-0,577$.

Percebe-se a tendência dos respondentes em assumir, em seu processo de formação de estratégias, uma postura que se aproxima predominantemente da visão determinista, porquanto se trata da forma como as organizações reagem frente à forte pressão exercida pelo ambiente, obrigando a formular e implementar suas estratégias face às condições e às restrições impostas pelo ambiente externo, Porter (1980). Essa postura alia-se às definições de Hitt \& Tyller (1991), do comportamento normativo formal, em que as estratégias são construídas por meio de planos formais, estimulados pela análise de oportunidades e ameaças do ambiente externo e forças e fraquezas do ambiente interno.

Considerando as ponderações de Hitt \& Tyller (1991), percebe-se que as IES respondentes tendem a apresentar comportamento mais próximo do processo formal, influenciadas fortemente pelas características do ambiente. Com efeito é possível indicar que as IES respondentes, em alguns momentos podem apresentar comportamento isomórfico de atuação organizacional, fato que conforme Hinings \& Greenwood (1989) fazem prevalecer às forças imitativas, normativas e coercitivas, determinando postura reativa e deliberada de formação de estratégia. Aldrich \& Pfeffer (1976) argumentam que, neste caso, as estratégias são selecionadas e impostas pelo ambiente.

\subsection{Análise Conjunta dos Indicadores}

$\mathrm{Na}$ análise conjunta, o teste Alplha de Cronbach demonstrou índice de confiabilidade de aproximadamente $67 \%$, o que demonstra que os indicadores, independente do grupo/bloco teórico que pertençam, apresenta resultados confiáveis.

Os resultados conjuntos dos dados demonstram que entre as quatro perspectivas teóricas (processo planejado, negociado, construção permanente e de mudanças) utilizadas por este trabalho que explicam o processo de formação de estratégias, a única que demonstrou consistência tanto pelas cargas fatoriais como pelas comunalidades geradas por seus indicadores isoladamente, foi o processo planejado de formação de estratégias.

Por meio dos dados analisados, foi possível perceber que existem evidências lógicas suficientes para dizer que o processo de formação de estratégias das IES pesquisadas considera o processo planejado um fator (F1) preponderante para a construção de suas estratégias, sendo guia para as decisões desta natureza.

Nesse ínterim, os pressupostos do fator planejado $(\mathrm{F} 1)$ são ratificados pela indicação das IES respondentes em assumir o grupo/bloco de indicadores que compreende a análise do contexto ambiental como elementos fundamentais para o seu processo estratégico, ainda que não apresente caráter de monitoramento e análise crítica destas variáveis, conforme sugerem Andrews (1971) e Porter (1980, 1985). A Figura 1 demonstra paralelamente o desempenho dos indicadores do ambiente geral e do ambiente tarefa. 
Figura 1 - Contribuições explicativas do contexto ambiental

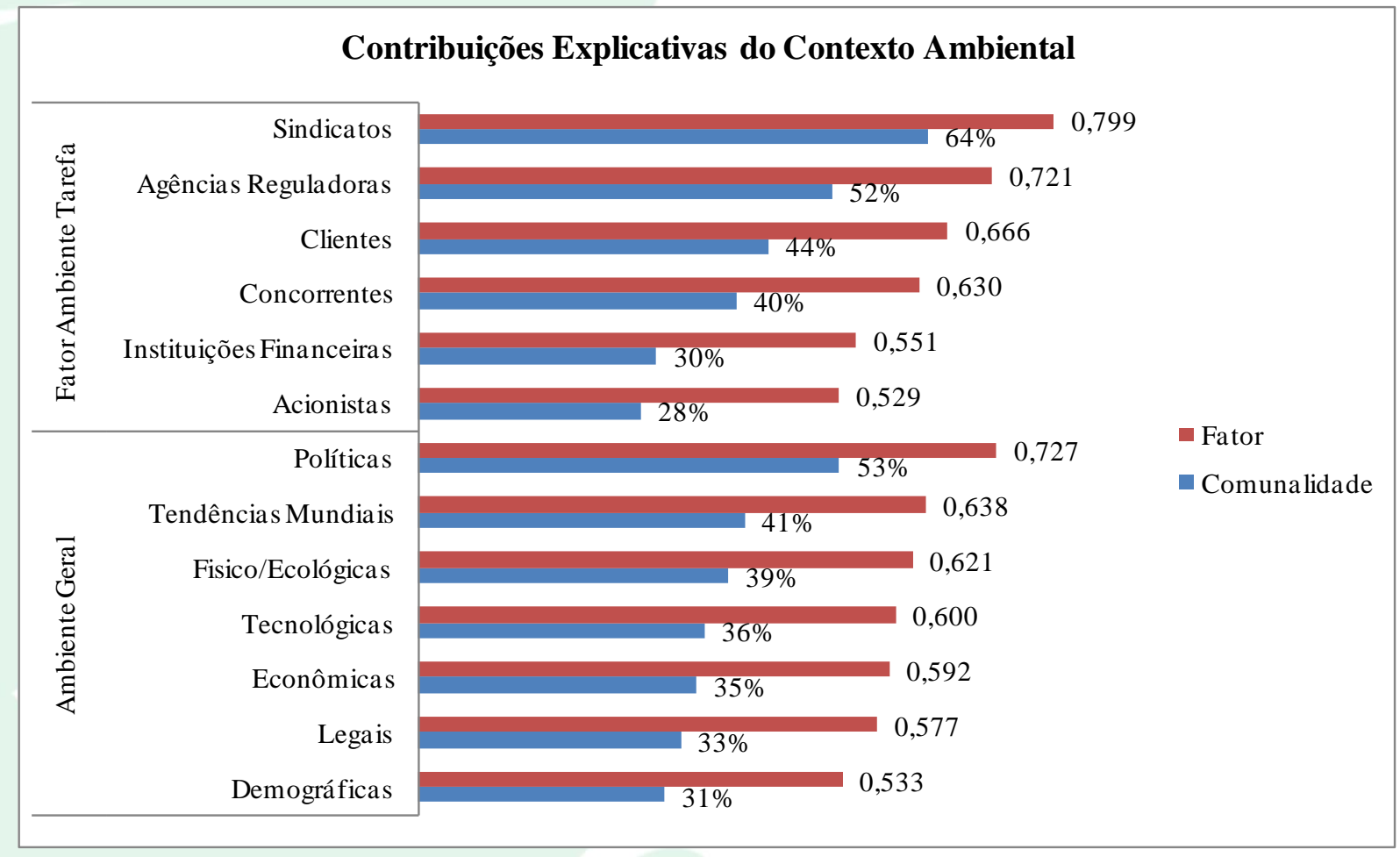

Fonte: os autores (2011).

A análise conjunta dos dados demonstrou que os indicadores do ambiente tarefa, confirmaram-se como um fator (F5) pelas cargas fatoriais e respectivas comunalidades geradas. Os indicadores do ambiente geral ficaram muito próximos de se caracterizarem como um fator (F6), entretanto, as cargas fatoriais analisadas conjuntamente não foram suficientes para tal feito.

A influência do contexto ambiental, seja do ambiente tarefa ou do ambiente geral, confirma as constatações de Mainardes; Alves; Raposo e Domingues (2010) quando constataram a interferência dos stakeholders no processo estratégico de uma universidade, independente de estarem localizados no ambiente tarefa ou no ambiente geral: alunos, governo nacional, agências reguladoras, organizações e instituições não governamentais, entidades de classe, etc.

Por fim, a análise geral dos 41 indicadores culminou no organograma representado através da Figura 2 que demonstra o design do processo real de formação de estratégia das IES pesquisadas, a partir das evidências lógicas analisadas até aqui. 
Figura 2 - Design do processo real de formação de estratégias

Processo Negociado

Processo de Mudança
X08 - Dirigentes determinam as estratégias

$\mathrm{X} 10$ - Mercado conduz as mudanças

$\mathrm{X} 12$ - Ambiente externo determina as direções

Ambiente Geral

Tendências Mundiais

Demográficas

Tecnológicas

Políticas

Físico/Ecológicas

Legais

Econômicas

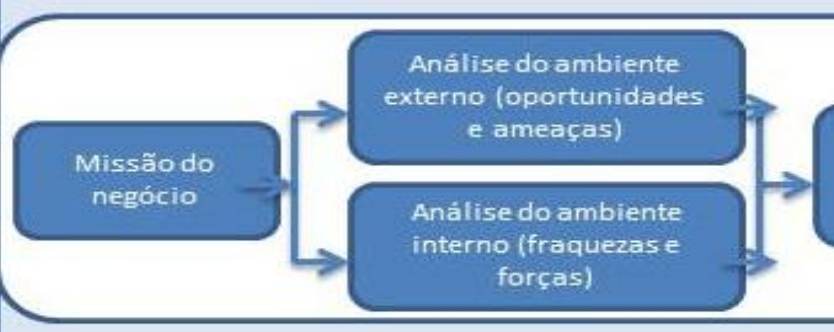

Fator Ambiente Tarefa $\left(\mathrm{F}_{5}\right)$

Clientes

Sindicatos

Fator Processo Planejado (F1)

Formulação

de metas

Formulação de estratégias

Formulação de programas

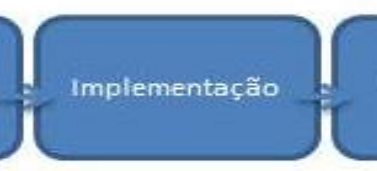

Feedback e Controle

C de prosemas

(20)

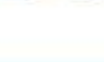

Agências Reguladoras Acionistas

X14 - Continuidade dos padrões de ação do passado

Processo de Construção Permanente

X15 - Imposição do ambiente

X25 - A alternativa estratégica impõe-se

Processo Negociado

X08 - Dirigentes determinam as estratégias

Fonte: os autores (2011). 
Observa-se, no centro do organograma, o fator processo planejado de formação de estratégias (F1) que é fortemente influenciado pelo fator ambiente tarefa (F5) e, consequentemente, pelas variáveis do ambiente geral. Percebe-se que o fator planejado (F1) recebe o impacto direto das restrições e dos movimentos do ambiente, verificadas pelas contribuições do processo de mudanças e construção permanente. Constatou-se que o processo estratégico das IES respondentes também é influenciado pela imposição dos dirigentes (X8).
$\mathrm{Na}$ análise multidimensional, demonstrada na Figura 3 observou-se a distribuição das IES representadas pelos respectivos números que foram ordenados de acordo com o retorno das pesquisas, antecedidas pela letra "A", o que demonstrou que a maioria das IES pesquisadas apresenta proximidade de respostas. Atesta-se, no mapa que esta maioria concentra-se entre a escala 1 e -2 variações que indicam grande conglomerado com 39 IES respondentes.

Figura 3 - Análise Miltidimensional

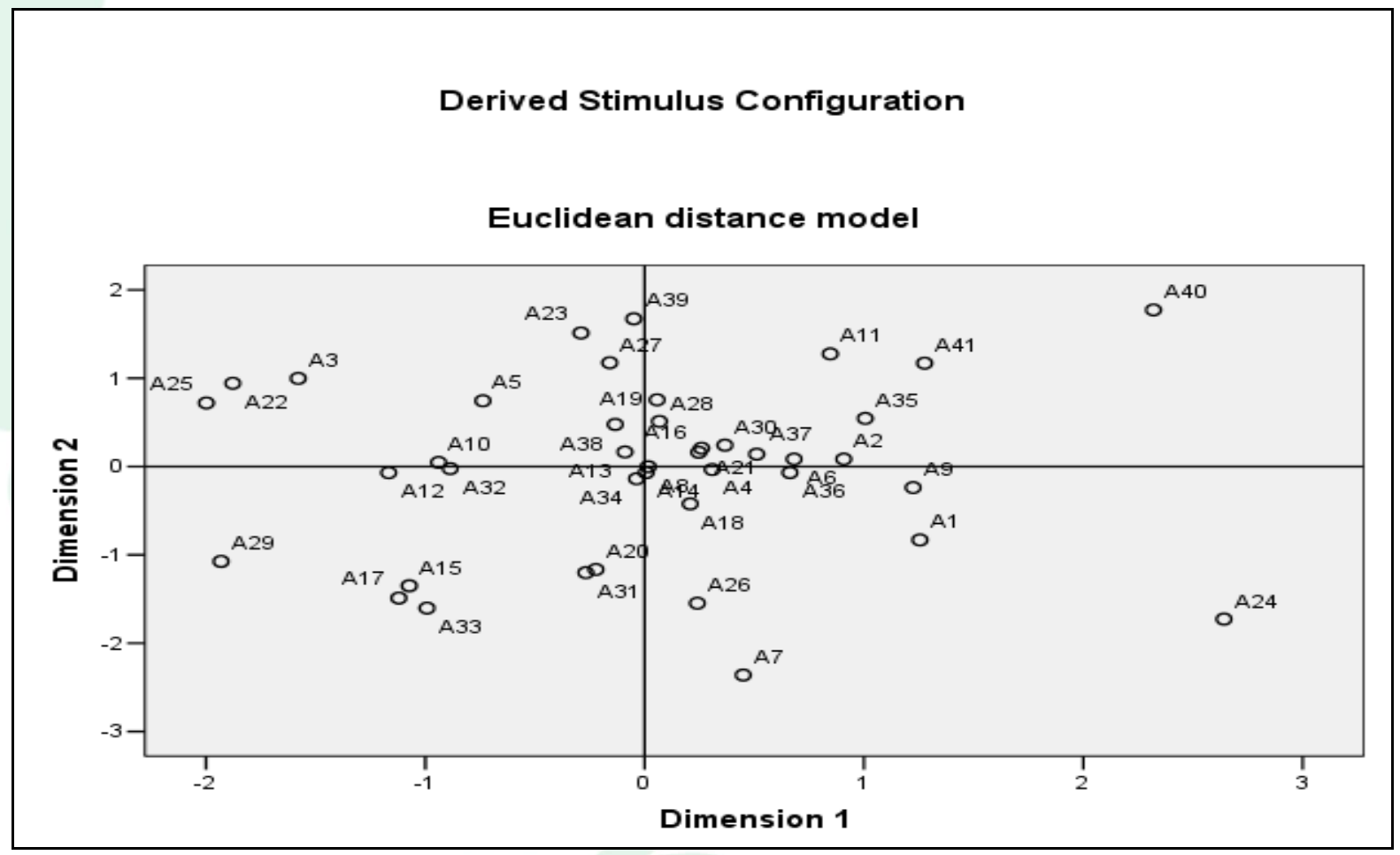

Fonte: os autores (2011).

Neste contexto, mostraram comportamento discrepante as IES “A40" e "A24". As duas situam-se em torno da escala 3, situando-se na extrema direita do mapa, a IES “A40" na parte superior e a IES “A24" na parte inferior. Constatando que as respostas atribuídas por estas IES nesta pesquisa, sinalizam um processo estratégico discrepante em relação às outras IES da amostra.

\section{CONSIDERAÇÕES FINAIS}

O presente trabalho teve por objetivo central o de conhecer o processo de formação de estratégias nas IES localizadas no Estado de Santa Catarina, através do uso do método survey com abordagem quantitativa, cuja análise valeu-se da estatística multivariada.
De acordo com os respondentes, pôde-se concluir que o processo de estratégia nas IES pesquisadas é (1) sustentado pelo processo planejado que conforme Ansoff (1965); Learned, Christensen, Andrews \& Guth, (1965); Andrews (1971); (2) afastase do processo como formação e aproxima-se do processo como formulação de estratégias, concernente as definições de Mintzberg (1978); Mintzberg, Ahlstrand \& Lampel (2000); (3) a formalidade é um elemento presente e preponderante no processo, aspecto que é fruto do processo sistemático e processual de formação de estratégias; (4) não obstante o processo seja essencialmente planejado, existem evidências que há estratégias que se aproximam do padrão emergente; (5) as estratégias apresentam tímida relação com padrões do passado, sugerindo nuances de aprendizado 
Além disso, conclui-se que as estratégias são (6) predominantemente determinadas pelo ambiente (comportamento determinista), indicando conduta reativa em relação às demandas estratégicas; (7) há momentos, no entanto que há interferência explícita dos dirigentes, impondo as estratégias, contrariando os fundamentos de Cyert \& March (1963); Simon (1971); Murray (1978) March e Simon (1981); Idemburg (1993); Mintzberg; Ahlstrand; Lampel (2000); (8) um grupo significativo de stakeholders foi identificado como influentes no processo de formação de estratégias, demonstrando a interferência do contexto ambiental no comportamento estratégico das IES pesquisadas.

A correlação que se estabelece em LDB e processo estratégicos das IES é forte, o que pode ser explicado pelas estratégias reativas que se destacaram na amostra investigada. É possível que o olhar mais cuidadoso das IES ao contexto ambiental tenha relação com as consequências que a Lei de Diretrizes e Bases para a Educação Nacional n. 9.394/96, desencadeou para o setor de educação superior. Houve intenso crescimento e proliferação de IES no país, por conseguinte, em Santa Catarina. (Esteves, 2007; INEP/MEC, 2008). Nesse contexto, Steiner (2010) sublinha que as IES de caráter privado, com fins lucrativos, foram as que mais ampliaram suas atividades, fato que pode estar indicando comportamento competitivo entre as IES de modo geral, independente de serem com fins lucrativos ou não.

Quanto às análises das hipóteses, notou-se que $\mathrm{H}_{1}$ foi rejeitada, visto que os dados deste estudo constataram o processo planejado como um fator. Sugeria a $\mathrm{H}_{1}$ que o processo estratégico das IES pesquisadas não apresentasse comportamento em que fosse possível afirmar em qual extremo estivessem, emergentes ou deliberadas. Contudo, o que se constatou foi um processo estratégico guiado pela formalidade, a tal ponto que as IES respondentes acenaram para o processo planejado de formação de estratégias como o fator mais relevante, levando este fator a explicar $43,88 \%$ do comportamento dos respondentes.

De igual modo a $\mathrm{H}_{2}$ foi refutada. Averiguou-se que o comportamento formal processual é predominante entre os pesquisados. Evidencias que sustentam novamente o fator planejado de formação de estratégias, em que as estratégias são o resultado do modelo mecanicista simples e controlado do planejamento formal.

Em face disso, o processo estratégico das IES respondentes afasta-se das premissas de estratégias emergentes sustentadas por Mintzberg (1978); Mintzberg \& Quinn (2001); Mintzberg, Ahlstrand \& Lampel (2000). Os autores sustentam que, por esta perspectiva, as IES deveriam assumir a possibilidade de que as estratégias fossem oriundas de um processo de aprendizado e criativo dos dirigentes.
A hipótese $\mathrm{H}_{3}$ indicava a possibilidade de a negociação estar em torno do processo estratégico das IES respondentes. O que se averiguou rejeita esta possibilidade, tendo em vista a carga fatorial e respectiva comunalidade verificada no indicador " $\mathrm{X} 8$ : Nossos dirigentes determinam nossa estratégia (0,999/63\%)", delineando comportamento impositivo e restritivo quanto a possibilidades de negociação das escolhas estratégicas.

Nota-se que em meio ao processo sistemático e planejado, há momentos, em que as estratégias mostram comportamento voluntarista por meio dos respectivos dirigentes. Este fato contraria as suposições teóricas do processo negociado verificados em Cyert; March (1963); Murray (1978); Idenburg (1993); Nicolau (2001), de que as estratégias são fruto de um processo social, que valoriza os sistemas de valores, acentuando a inclusão dos indivíduos e de grupos sociais internos da organização no processo de formação de estratégicas.

$\mathrm{Na}$ hipótese $\mathrm{H}_{4}$ sugeria-se que o contexto ambiental determinasse o comportamento estratégico das IES respondentes. Esta inferência mostrou-se ser verdadeira, aceitando a H4. Os indicadores a seguir, pelas cargas fatoriais e comunalidades, expressam e justificam o aceite da H4: "X10: Não temos como mudar nosso ambiente de negócios, somos conduzidos pelo mercado $(0,877 / 77 \%)$ ", "X12: Nossa liberdade para fazer escolhas é restringida porque o ambiente externo à empresa (mercado, concorrência, governo, etc.)", "X15: Nossas estratégias são o reflexo da reação às dificuldades impostas pelo ambiente $(0,687 / 47 \%)$ " e "X25: À época da adoção da estratégia, as opções estratégias eram limitadas".

Por fim, há evidências lógicas para que a $\mathrm{H}_{5}$ seja aceita por este estudo, uma vez que ao averiguar que a soma das comunalidades do ambiente tarefa e do ambiente geral atingiram uma capacidade explicativa em torno de $71 \%$, sugerindo que aproximadamente $71 \%$ do comportamento estratégico das IES pesquisadas pode estar sendo afetado pelo contexto ambiental.

É válido reconhecer que no presente estudo encontraram-se limitações. Observou-se na análise multidimensional, que demonstrou proximidades de comportamento em grande parte das IES pesquisadas, todavia, não o suficiente para sugerir que exista padrão linear que explique satisfatoriamente o processo estratégico de todas as IES reapresentadas pela amostra.

Os estudos sobre o processo da estratégia são empiricamente complexos e, por consequência, polêmicos. Empiricamente complexos porque necessitam da apreensão de muitas variáveis. Polêmicos porque permitem diversas interpretações. Para Pettigrew (1992), as pesquisas sobre processo das estratégias são estreitas quanto à sua ótica de análise. Considera-se, destarte, que os resultados refletem o ponto de vista de alguns dirigentes de um número finito 
de IES, não podem ser generalizados para todo o universo de IES.

Recomenda-se, para trabalhos posteriores, a análise do processo de criação de estratégias em um número maior de IES, como, por exemplo, nas IES situadas no Sul do país ou, até, em todo o país. Desse modo atenderá a recomendação estatística de ter 5 respondentes por assertiva, para dar validade estatística ao uso da técnica análise fatorial exploratória. Pequenas amostras são frágeis e ampliam as limitações de um estudo científico quantitativo. Outra possibilidade é aprofundar os estudos que correlacionam a LDB 9.394/96 e o processo estratégico das IES. O uso de entrevistas em profundidade para compreender o processo estratégicos de IES de excelência e centenárias pode enriquecer as dimensões de análise do contexto estratégico desse tipo de organizações. E ainda, estudo de casos múltiplos comparando estratégias de IES inovadoras e que adotam estratégias diferentes para se manterem no mercado, pode ser um estudo motivador. Essa alternativa permitirá ampliar a ótica do comportamento estratégico das IES para outros horizontes, permitindo extrair com mais amplitude as características que norteiam o processo estratégico desta tipologia de organização.

\section{REFERÊNCIAS}

Aguiar, A. B., \& Frezatti, F. (2014). Uso de medidas não financeiras de desempenho, estratégia e orientação temporal de gestores das "Melhores empresas para você trabalhar"e. REAd. Revista Eletrônica de Administração, 20(1), 114-139.

Andrade, M. M. (2002). Introdução à metodologia do trabalho científico. São Paulo: Atlas.

Andrews, K. (1971). The concept of strategy. Homewood, IL: Irwin.

Ansoff, H, I. (1965). Corporate strategy. New York, NY: McGraw-Hill.

Barney, J. B., \& Hesterly, W. (2006). Organizational economics: Understanding the relationship between organizations and economic analysis. The SAGE handbook of organization studies, 110-148.

Brasil. Censo do Ensino Superior 2005. 2006. Disponível em: <www.inep.gov.br>. Acesso em: 02 dez 2009.

Brasil. Inep - Instituto Nacional de Estudos e Pesquisas em Educacionais Anísio Teixeira. (2014). Censo da educação superior 2012: resumo técnico. Brasília, DF: INEP. Disponível em: <www.inep.gov.br>. Acesso em: 02 dez 2009.

Brito, R. P., \& Oliveira, L. B. (2016). A Relação entre Gestão de Recursos Humanos e Desempenho Organizacional. Brazilian Business Review, 13(3), 95-115.

Campos, I. F., \& Verni, M. L. (2006). Gestão Universitária: uma analogia do ponto de vista de dinossauros, gazelas e tigres em três instituições de ensino superior privado. In: VI Colóquio Internacional Sobre Gestão Universitária $\mathrm{Na}$ América Do Sul, 6, 2006, Blumenau. Anais... Blumenau: FURB.

Capalonga, G., Diehl, C. A., \& Zanini, F. A. M. (2014). Estratégias percebidas sob o foco da teoria de posicionamento estratégico, da visão baseada em recursos, da missão estratégica e da tipologia organizacional: um estudo com empresas do Sul do Brasil. Brazilian Business Review, 11(3), 29-55.

Cardoso, A. L. J., \& Kato, H. T. (2015). Análise das publicações sobre capacidades dinâmicas entre 1992 e 2012: discussões sobre a evolução conceitual e as contribuições dos autores de maior notoriedade na área. Revista de Administração Mackenzie, 16(3), 201-237.

Carneiro, J. M. T., Cavalcanti, M. A. F. D., \& Silva, J. F. D. (1997). Porter revisitado: análise crítica da tipologia estratégica do mestre. Revista de Administração Contemporânea, 1(3), 7-30.

Carvalho, D. M., Prévot, F., \& Machado, J. A. D. (2014). O uso da teoria da Visão Baseada em Recursos em propriedades rurais: uma revisão sistemática da literatura. Revista de Administração, 49(3), 506-518.

Collis, J., \& Hussey, R.. (2005). Pesquisa em Administração: um guia prático para alunos de graduação e pós-graduação. $2^{\mathrm{a}}$ ed. Porto Alegre: Bookeman, 2005.

Colossi, N., Consentino, A., \& Queiroz, E. G. (2001). Mudanças no contexto do ensino superior no Brasil: uma tendência ao ensino colaborativo. Revista FAE, 4(1), 57-58.

Conke, L. S. (2013). O Pensamento Estratégico no Século XX: Explicações Históricas. Revista IberoAmericana de Estratégia, 12(4), 210.

Cyert, R.M., \& March, J.G. (1963). A behavioral theory of the firm. Englewwoo Cliffs, N.J: PrenticeHall. 
Córcoles, Y. R. \& Ponce, Á. T. Cost-benefit analysis of intellectual capital disclosure: University stakeholders' view. Revista de Contabilidad Spanish Accounting Review (RC-SAR), v.16, n.2, June-December 2013, p.106-117,

Denis, J.-L., Langley, A., \& Rouleau, L. (2007). Strategizing in pluralistic contexts: rethinking theoretical frames. Human Relations, 60(1), 179215

Drucker, P. F. (1954). The practice of management. New York: Oxford University Press.

Ensslin, L., Dutra, A., Martins, R. P., \& Dezem, V. (2016). Modelo Construtivista para Apoiar o Processo de Gestão da Universidade Federal de Tocantins . Revista Ibero-Americana de Estratégia, $15(2), 122-129$.

Esteves, P. C. L. (2007). Fatores determinantes de mudanças na estrutura competitiva do sistema de ensino superior de Santa Catarina. 2007. 154f. Tese (Doutorado em Engenharia da Produção) Universidade Federal de Santa Catarina, Florianópolis.

Fachinelli, A. C., \& Alberdi, A. M. (2014). Integridade estrutural da Inteligência Estratégica: uma avaliação em uma Corporação Cooperativa. Brazilian Business Review, 11(3), 81-105.

Faoro, R. R., Olea, P. M., Roesch, S. M. A., \& Abreu, M. F. (2014). Diferenciação e foco para obtenção de vantagem competitiva: o caso da Beta Sistemas. REAd. Revista Eletrônica de Administração, 20(3), 838-856.

Faria, A. A., Imasato, T., \& Guedes, A. L. M. (2014). O que Gestão Estratégica tem a ver com capitalismo(s)? . Revista de Administração Contemporânea, 18(Ed.Esp.), 1-21.

Hair Jr, J. F., Babin, B., Money, Arthur H., \& Samuel, P. (2005). Fundamentos de métodos de pesquisa em administração. - tradução Lene B. Ribeiro. - Porto Alegre: Bookman

Idenburg, P. J. (1993). Four styles of strategy development. Long range planning, 26(6), 132-137.

LDB - Lei das Diretrizes e Bases da Educação Nacional n. 9.394, de 20 de dezembro de 1996. Diário Oficial da União, Brasília, DF, 23 dez. 1996. Seção 1, p.27.839.

Learned, E. P., Christensen, C. R., Andrews, K. R., \& Guth, W. D. (1969). Business policy: Text and cases. Homewood, IL: RD Irwin.
Lima, P. S. H., Lima, C. R. M., Dias, I. A., \& Lima, M. V. A. (2016). Yield Management em Instituições de Ensino Superior: um Estudo de Caso na Modalidade de Ensino a Distância de uma Universidade Comunitária. Revista IberoAmericana de Estratégia, 15(3), 70-87.

Martins, E. S., Rosseto, C. R., Lima, N. C., \& Penedo, A. S. T. (2014). Comportamento estratégico e ambidestria: um estudo aplicado junto às empresas vinícolas brasileiras. Revista Brasileira de Gestão de Negócios, 16(52), 392-415.

Meyer Jr., V., \& Murphy, J.P. (2000). Dinossauros, gazelas e tigres: novas abordagens da administração universitária. São Paulo: Insular.

Mintzberg, H. (2006). Ascensão e queda do planejamento estratégico. Porto Alegre: Bookman.

Mintzberg, H., Ahlstrand, B., \& Lampel, J. (2000). Safári de estratégia: um roteiro pela selva do planejamento estratégico. Porto Alegre: Bookman.

Mintzberg, H., \& Mchugh, (1985). A. Strategy formation in an adhocracy. Administrative Science Quarterly, v.30, n. 2, p. 160-197, jun..

Mintzberg, H., \& Quinn, J. B. (2001). O processo da estratégia. 3. ed. Porto Alegre: Bookman, 2001.

Miragaia, D. A. M., Ferreira, J., \& Carreira, A. (2014). Do stakeholders matter in strategic decision making of a sports organization?. Revista de Administração de Empresas, 54(6), 647-658.

Montenegro, L.M.; Bulgacov, S. (2015). Governança e estratégia no curso de graduação em administração na perspectiva da teoria do ator-rede. Revista Administração Contemporânea. Rio de Janeiro, v. 19, n. 2, art. 3, pp. 212-231, Mar./Abr.

Morais, N. M., Forte, S. H. A. C., Oliveira, O. V., \& Sobreira, M. C. (2015). Proposição de método para avaliar a maturidade do processo de cenários nas organizações. Revista de Administração Mackenzie, 16(2), 214-244.

Murray, E. A. (1978). Strategic choice as a negociated outcome. Management Science, 24(9), 961-972.

Nicolau, I. (2001). O conceito de estratégia. Instituto Superior de Ciências do Trabalho e da Empresa (ISCTC). Lisboa.

Oliveira, Francisco Estevam Martins (2007). SPSS Básico para análise de dados. Rio de Janeiro: Editora Ciência Moderna Ltda. 
Oliveira Junior, A. B., Borini, F. M., Bernardes, R. C., \& Oliveira, M. J. (2016). Impact of entrepreneurial orientation on strategic alliances and the role of top management. Revista de Administração de Empresas, 56(3), 315-329.

Palácios, F. A. C.(2015). Proposta de esquema analítico para o processo estratégico - $\mathrm{O}$ caso de uma universidade pública. Revista de Administração Mackenzie, 16(2), 127-156.

Pereira, M. I., \& Santos, S. A. (2001). Modelos de gestão: uma análise conceitual. São Paulo: Pioneira Thomson Learning.

Pettigrew, A.M. (1987). Context and action in the transformation of the firm. Journal of Management Studies, 24(6), 649-670.

(1977). Strategy formulation as a political process. International Studies of Management \& Organization, 7(2), 78-87.

Pinto, R. F., Guerrazzi, L. A. C., Serra, B. P. C., \& Kniess, C. T. (2016). A Pesquisa em Administração Estratégica: um Estudo Bibliométrico em Periódicos Internacionais de Estratégia no Período de 2008 a 2013. Revista Ibero-Americana de Estratégia, 15(2), 22-37.

Porter, M. E. (1980). Competitive strategy: techniques for analyzing industries and competitors. New York : Free Press.

(1985). Competitive Advantage: creating and sustaining superior performance, The Free Press, New York.

Porto, C., \& Régnier, K. (2003). Cenários do ensino superior no Brasil e no mundo - condicionantes, tendências e cenários para o horizonte 2003-2025. Brasília: MEC.

Rebelo, L. M. B. A.; Coelho, C. S. R.; Erdmann, R. H. (2005). Edificação de um construto teórico sobre processo de formação de estratégias de gestão em instituições de ensino superior (IES) à luz dos pressupostos da teoria da complexidade. In: Encontro Da Associação Nacional De PósGraduação Em Administração- Enanpad, 27, 2005, Brasília. Anais... Brasília: ANPAD.

Rodrigues, M. A. S., Chimenti, P., Nogueira, A. R. R., Vaz, L. F. H., \& Repsold, A. (2014). From print to screen: changes and challenges facing the Brazilian publishing industry. Revista de Administração, 49(3), 491-505.

Roesch, S.M.A. (1999). Projetos de estágio e de pesquisa em administração. São Paulo: Atlas.
Rudio, F. V. (1986). Introdução ao projeto de pesquisa científica. Petrópolis: Vozes.

Sampaio, R. M., \& Laniado, R. N. (2009). Uma experiência de mudança da gestão universitária: o percurso ambivalente entre proposições e realizações. Rev Adm Pública, 4(1), 151-74.

Santini, F. O., Ladeira, W. J., Araújo, C. F., \& Finkler, E. N. R. (2015). A relação entre percepção de valor e retenção: uma análise entre faculdades e universidades particulares. Revista de Gestão, 22(3), 417-434.

Simon, H. A. (1947). Administrative behavior: a study of decision-making processes. New York: MacMillan.

. (1971). Comportamento administrativo. 2. ed. Rio de Janeiro: FGV.

Stallivieri, L. (2003). O Sistema de Ensino Superior do Brasil características, tendências e perspectivas. Caxias do Sul: FUNDAI, UCS.

Steiner, G.A. (1969). Top management planning. New York: MacMillan.

Steiner, J. E. (2006). Diferenciação e classificação das instituições de ensino superior no Brasil. Ensino Superior. Conceito e Dinâmica. São Paulo: Edusp.

Vahl, T., Meyer, J. V.; Finger, A. P. (1989). Desafios da administração universitária. Florianópolis: Editora UFSC.

Vergara, S. C. (1998). Projetos e relatórios de pesquisa em administração. São Paulo: Atlas, 1998.

Wilson, R.P. (1995). The forading behaviour of the african penguin spheniscus demersus. In Dann, P.; Norman, I.; Reilly, P. The Penguins: Ecology and Management. Surrey Beatty \& Sons Pty Ltda, Australia.

Wright, P. L., Kroll, M. J., \& Parnell, J. A. (1998). Strategic management: concepts and cases. Prentice Hall. 